\title{
The Impact of COVID-19 Psychological Distress on Students' Academic Challenges in University
}

\author{
Kate Shostak, ${ }^{1}$ Allyson Hadwin and Paweena Sukawahanakul \\ kate.shostak1@gmail.com
}

\begin{abstract}
The COVID-19 pandemic has introduced significant disruptions in the learning environment for many post-secondary students with many shifting entirely to remote online learning, which can compound existing academic challenges. While emerging evidence has suggested that COVID-19 impacts students' well-being and stress, little is known about how the pandemic has affected students academically. This study investigates how different types of academic challenges mediate the relationship between students' COVID-19 psychological distress and their academic performance. Participants $(n=496)$ completed an online survey that measured COVID-19 psychological distress, self-reported grade point average (GPA), and academic challenges. Mediational analyses estimating indirect pathways were conducted using structural equation modelling on Mplus. Our results showed that all challenges increased along with COVID-19 distress, but specific challenges had a significant relationship with the expected GPA. We found that out of the five academic challenge areas, metacognitive, motivational, and social and emotional challenges emerged as the salient challenge areas that fully mediated the relationship between COVID-19 distress and GPA. Contrary to our prediction, while more significant COVID19 distress predicted more social and emotional challenges, these challenges were associated to higher GPA. Future research is invited to help students manage and cope with their academic challenges.
\end{abstract}

Keywords: academic challenges; university students; COVID-19; stress; well-being, GPA; self-regulated learning; remote learning

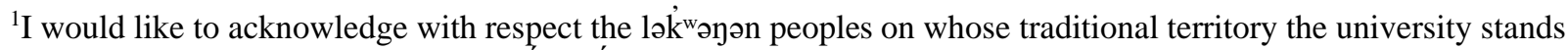
and the Songhees, Esquimalt and WSÁNEĆ peoples whose historical relationships with the land continue to this day.

Thank you to the University of Victoria for supporting this research through the Jamie Cassels Undergraduate Research Award. This research was supported in part by Social Sciences and Humanities Research Council of Canada (SSHRC) grants (Hadwin, PI), and SSHRC partnership grant (Stewart, PI; Hadwin, CoI).

Finally, thank you to the wonderful Technology Integration and Evaluation Research team for the support and guidance, specifically, Allyson Hadwin, Paweena Sukhawthankul, Ramin Rastampour, and Michelle Bahena Olivares.
} 


\section{The Impact of COVID-19 Psychological Distress on Students' Academic Challenges in University}

The COVID-19 pandemic has created a significant shift worldwide. Undergraduate students face a new version of learning: remote COVID-19 learning (RCL). RCL is unlike typical online learning; for example, students collaborate with classmates on video platforms or discussion boards and must complete virtual assignments from different time zones. Studies show that students have reported negative perceptions towards the RCL shift as they face unfamiliar psychological and environmental obstacles (Blizak et al., 2020). For instance, technical difficulties during an exam can contribute to distress and anxiety. While distress and anxiety are standard features of being a student, students also have to grapple with this shift that may impact their studies, their ability to graduate on time, and their employment prospects (Cao et al., 2020).

On top of adjusting to the new learning style and balancing their course loads, students also face personal psychological distress due to the COVID-19 outbreak. Consequently, the psychological distress may impact their academic performance. These unprecedented events may have increased stress drastically without students noticing. Studies have consistently shown that stress impacts academic performance (Brackney \& Karabenick, 1995; Lloyd et al., 1980; Schraml et al., 2012). For example, students experiencing chronic stress showed worse grades than students who were experiencing little to no stress (Schraml et al., 2012). Emerging evidence suggests that the increased amount of stress introduced by the pandemic may be impacting students' academic performance and engagement (Meo et al., 2020). Students have reported that their distress is aligned with personal issues; for instance, concerns about income and living with immunocompromised individual(s) (Cao. et al., 2020). These expected pandemic stressors contribute to feelings of emotional detachment related to decreased duration of study time and overall work performance (Meo et al., 2020). Further, during the RCL era, students reported an increase in procrastination and troubles related to focusing, which were related to anxiety and guilt (Li et al., 2021). The increased stress arising from personal and environmental factors can negatively affect students' overall well-being.

It is reported that individuals face poorer mental health and well-being during the pandemic (Hasan \& Bao, 2020; Meo et al., 2020). One factor contributing to this relationship is social isolation and distancing (Kim \& Jung, 2020). Students have reported that the new common practice of social isolation and distancing have caused mood swings and symptoms of depression (Li et al., 2021). Individuals' perception of isolation is related to being disconnected from friends and family, losing autonomy, experiencing doubts about the world, and developing intense feelings (Meo et al., 2020). Emotional impacts commonly reported, such as feelings of seclusion, helplessness, panic attacks, impacting sleep schedules and eating habits (Li et al., 2021), overlap with symptoms of depression (Son et al., 2020). During the pandemic, students have shown a significant increase in reported anxiety towards the future (Cao et al., 2020) and lower mental well-being and life orientation (Dodd et al., 2021). The lack of interpersonal communication during the pandemic likely aggravates symptoms among students who already suffer from anxiety disorders (Cao et al., 2020).

Environmental and personal stress may impact students' learning behaviours, and increased anxiety and depression during the pandemic could be associated with ineffective study plans (Hasan \& Bao, 2020). Individuals have reported engaging in maladaptive coping behaviours during the COVID-19 pandemic and identifying these areas may allow for planning and designing a support system (Son et al., 2020). For instance, students who have been practicing social 
distancing for an extended period have reported decreased psychological well-being and decreased effective learning behaviours (Meo et al., 2021). An essential tool for students to thrive in an online environment is self-efficacy because they must execute behaviours alone (Cho \& Shen, 2013). However, since students are experiencing an enormous amount of stress, this will lead to lower self-efficacy (Brackney \& Karabenick, 1995). A way to boost self-efficacy is through the power of social interaction (Cho \& Shen, 2013). However, as that is not an option for students during the pandemic, the reduced self-efficacy will likely decrease higher-order learning strategies (Brackney \& Karabenick, 1995).

Current research on COVID-19 shows the pandemic impacts students' mental health, yet little is known about how it impacts academic challenges. Challenges in traditional face-to-face settings are likely compounded during the pandemic. Research shows academic challenges are multi-faceted; for example, Weinstein's strategic learning model states skill, will, and selfregulation explain academic success (Weinstein et al., 2011, 2000).

Skill refers to knowledge, thinking process, and strategies; academic challenges that overlap with skill are cognitive and metacognitive challenges. Cognitive challenges can include learning, remembering, communicating, and understanding course material and concepts (Weinstein et al., 2011, 2000). Metacognitive challenges include difficulties that relate to planning and monitoring tasks. Metacognitive factors include (1) planning by developing strong task understanding, (2) self-monitoring and self-awareness about what is working, and (3) strategy knowledge and choice (Weinstein et al., 2011, 2000).

Challenges related to will involve motivational and affective components of strategic learning that influence academic success. Motivational challenges include will, desire, and confidence to exert effort while studying. Having the persistence and motivation to complete school can be difficult for students (Weinstein et al., 2011, 2000). However, students who have powerful motivational qualities see increased academic success (Dörrenbächer \& Perels, 2016). Challenges related to self-regulation include difficulties related to the management of the learning process, which involves monitoring, evaluating, and adapting learning (Weinstein et al., 2011).

In addition to the three challenges in the Weinstein model, there are two additional challenges, behavioural and socio-emotional factors, which can also impact academic success. Behavioural challenges include difficulties with structuring learning environments, such as time management and exam preparation (Weinstein et al., 2011, 2000). Socio-emotional challenges may include emotional problems such as anxiety and stress (Weinstein et al., 2011, 2000). Socioemotional factors touch on how students are feeling, not just how they are acting. Emotions can impact a student's learning process significantly. Negative emotions, like anxiety, may impact academic achievement by reducing intrinsic motivation and producing task-irrelevant thinking (Pekrun et al., 2002).

Academic challenges are significant in the context of COVID-19, as they may explain the relationship between COVID-19 distress and academic performance. RCL is a new learning environment for students. Typically, when students transition into a new situation and environment, they face new challenges and may not have the tools to cope. Consequently, significant transitions cause students to struggle to cope with academic challenges (Hadwin et al., 2019); for example, students transitioning into an independent learning environment is deemed challenging (Briggs et al., 2012). Successful university students adjust their learning process to meet unfamiliar challenges (Winne \& Hadwin, 2008). Strong learners choose and personalize strategies for challenges rather than using the same approach for each task (Hadwin et al., 2001). 
It is challenging to design and support students in their academic challenges without understanding the specific problems in their academic work (Hadwin et al., 2019). Understanding what academic challenges have increased due to COVID-19 will allow research to narrow down interventions to help students cope and manage these areas. One possible way to help students manage academic challenges is to teach them how to engage in self-regulated learning (SRL). SRL allows students to engage and control their own learning process (Jansen et al., 2019). The process of being a self-regulated learner requires the student to monitor their task and performance then reflect on the outcome. This process repeats itself as the students uses the reflection period to adjust and prepare for the next task (Winne, 2018). Self-regulatory theorists discuss the importance of understanding specific academic challenges students encounter to develop interventions and supporting materials that have the potential to help students adapt (Hadwin et al., 2019). In an online setting, SRL helps students to monitor their own learning and goals, thus, achieving better learning outcomes (Santhanam et al., 2008). Further, self-regulation is essential for students' success within an online environment (Cho \& Kim, 2013).

This study investigates how different academic challenges (cognitive, motivational, socioemotional, metacognitive, and behavioural) mediate the relationship between COVID-19 psychological distress and academic performance. We hypothesized that (1) academic challenges can explain why COVID-19 psychological distress impacts academic performance, and (2) academic challenges will mediate the relationship between COVID-19 psychological distress and academic performance.

\section{Participants}

\section{Methods}

Participants $(N=496)$ were recruited from three groups of students: (a) enrolled in an academic course on learning strategies for university success (ED-D101), (b) participating in the psychology research pool, or (c) accessing a learning strategies library resource available to all students at the University of Victoria. Students from ED-D101 were required to participate in this study to receive credit in their class and complete a project. Participants taken from the psychology research pool who completed the survey and were given extra course credit through the SONA System. The SONA System is a cloud-based research and participant management solution for university. Further, the SONA System helps researchers easily recruit participants, set up studies, and generate course credit reports.

\section{Procedure}

Participants completed an online survey created using LimeWire that included measures of COVID-19 psychological distress, self-reported expected grade point average (GPA), and academic challenges (Hadwin, 2020). After the survey, students were given a personalized academic challenge report that allowed them to understand their learning habits and challenges. Debrief sessions were completed online using Zoom. Participants had to attend the debrief session to receive their promised compensation. This study was approved by the UVic Human Research Ethics Board, who examined this research protocol and concluded that, in all respects, the proposed research met the appropriate standards of ethics as outlines by the University of Victoria Research Regulations Involving Human Participants (19-0038-08). 


\section{Measures}

COVID-19 psychological distress was measured using the COVID-19 Peritraumatic Distress Index (CPDI). CPDI focuses on the frequency of anxiety, depression, physical symptoms, specific phobias, cognitive chance, avoidance and compulsive behaviours, and loss of functioning in the past week. Students were asked to rate 24 statements ranging from -2 (not at all) to 2 (extremely) (Qiu et al., 2020).

Self-reported GPA was reported with three questions (1) What overall GPA (average grade) do you expect to get this year? (2) How important is that GPA for you? and (3) How confident are you that you will attain that GPA?

Academic challenges were measured using the challenges subscale in Hadwin et al. (2021) self-regulated learning assessment and self-diagnostic tool (SRL-ASD). Students were asked to rate their level of agreement with eight statements on a 5-point Likert scale from -2 (strongly disagree) to 2 (strongly agree).

Mediational analyses estimating indirect pathways were conducted using structural equation modeling on Mplus.

\section{Descriptive Statistics}

\section{Results}

Table 1 provides mean and standard deviations on all variables for all participants and bivariate correlations for the full sample. On average, students reported experiencing higher levels of academic challenges indicated by mean scores greater than zero; with, motivational $(\mu=2.06$, $\sigma=5.00)$ and socioemotional $(\mu=4.20, \sigma=8.44)$ challenges reported as most problematic. On average, individuals did not report high levels of COVID-19 distress with the mean below zero $(\mu=-11.05)$. However, there was large variability in COVID-19 distress scores across individuals $(\sigma=18.34)$.

\section{Table 1}

Descriptive Statistics and Bivariate Correlations

\begin{tabular}{|l|r|r|r|r|r|r|r|r|r|}
\hline \multicolumn{1}{|c|}{ Variables } & \multicolumn{1}{c|}{ SD } & \multicolumn{1}{c|}{ Mean } & \multicolumn{1}{c|}{$\mathbf{1}$} & \multicolumn{1}{c|}{$\mathbf{2}$} & $\mathbf{3}$ & $\mathbf{4}$ & $\mathbf{5}$ & $\mathbf{6}$ & $\mathbf{7}$ \\
\hline Expected GPA & 0.807 & 3.41 & 1 & & & & & & \\
\hline $\begin{array}{l}\text { Motivational } \\
\text { Challenges }\end{array}$ & 5.00482 & 2.0644 & -0.227 & 1 & & & & & \\
\hline $\begin{array}{l}\text { Behavioural } \\
\text { Challenges }\end{array}$ & 6.29894 & 0.8129 & $-.147^{* *}$ & $.570^{* *}$ & 1 & & & & \\
\hline $\begin{array}{l}\text { Cognitive } \\
\text { Challenges }\end{array}$ & 5.8191 & 1.0543 & $-.227^{* *}$ & $.644^{* *}$ & $.588^{* *}$ & 1 & & & \\
\hline $\begin{array}{l}\text { Socioemotional } \\
\text { Challenges }\end{array}$ & 8.43881 & 4.2012 & $-.126^{* *}$ & $.597^{* *}$ & $.515^{* *}$ & $.486^{* *}$ & 1 & & \\
\hline $\begin{array}{l}\text { Metacognitive } \\
\text { Challenges }\end{array}$ & 8.03314 & 0.328 & $-.267^{* *}$ & $.587^{* *}$ & $.558^{* *}$ & $.665^{* *}$ & $.613^{* *}$ & & 1 \\
\hline $\begin{array}{l}\text { COVID -10 } \\
\text { Stressors }\end{array}$ & 18.34238 & -11.0202 & $-.123^{* *}$ & $.252^{* *}$ & $.218^{* *}$ & $.203^{* *}$ & $.418^{* *}$ & $.266^{* *}$ & 1 \\
\hline
\end{tabular}

Note. $* *$ Correlation is significant at the 0.01 level (2-tailed). 


\section{Structural Equation Mediation Model}

Initially, direct pathways between COVID-19 distress and expected GPA were examined first before the addition of academic challenges. As Figure 1 illustrates, the standardized regression coefficient between COVID-19 distress and expected GPA was statistically significant. COVID19 distress was negatively correlated with expected GPA. The negative correlation highlights that as COVID-19 distress increases, students' grades may lower $\left(a_{1}=-.12, \mathrm{p}<.01\right)$.

\section{Figure 1}

Association Between COVID-19 Distress and Expected GPA

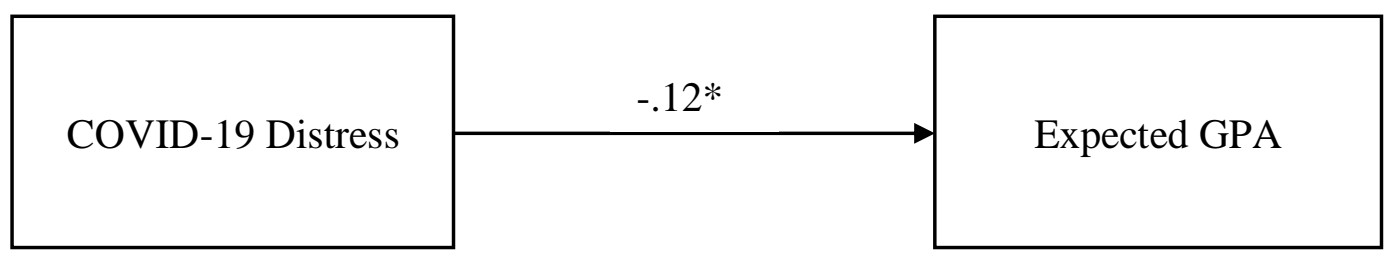

Note. ${ }^{*} p<.01$

Next, academic challenges was included in the model as a mediator between COVID-19 distress and expected GPA. As Figure 2 illustrates, the relationship between COVID-19 distress and expected GPA was fully mediated by academic challenges as the relationship between COVID-19 distress and expected GPA was no longer significant. Specifically, COVID-19 distress predicted greater levels of academic challenges $\left(b_{1}=.35^{*}, \mathrm{p}<.001\right)$, which in turn predicted lower $\operatorname{GPA}\left(c_{1}=-.22^{*}, \mathrm{p}<.001\right)$.

Figure 2

Mediating Effect of Global Academic Challenges on the Relationship Between COVID-19 Distress and Self-Reported GPA

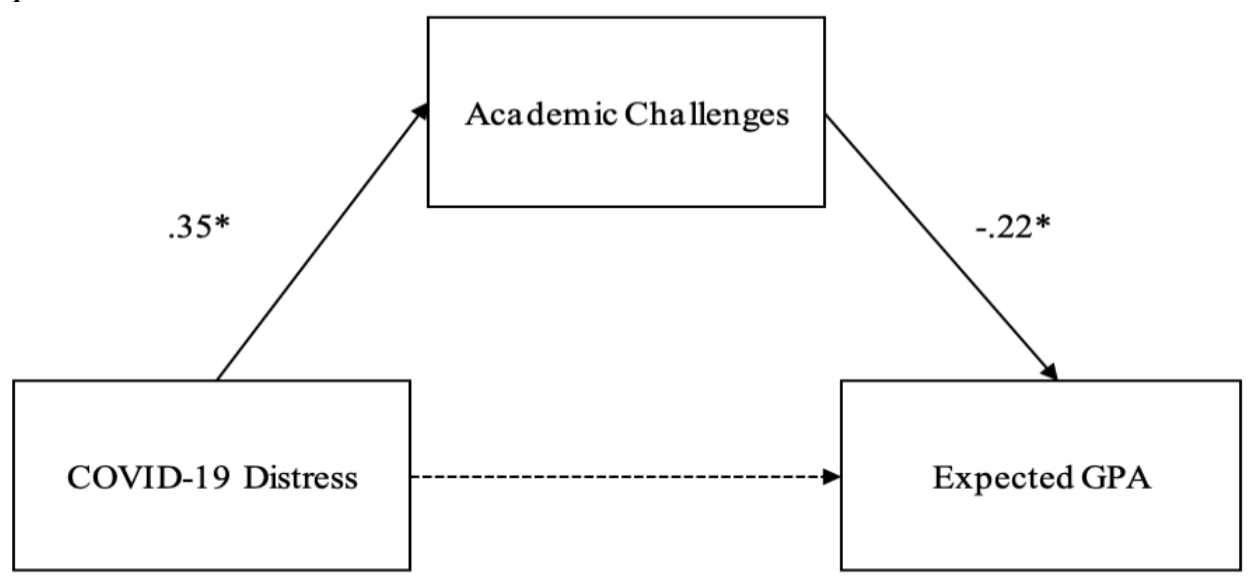

Note. Dashed lines represent nonsignificant pathways. ${ }^{*} p<.001$ 
Finally, specific academic challenges, cognitive, motivational, social and emotional, behavioural, and metacognitive, were analyzed to determine their unique contribution to COVID19 distress and GPA. Over and above the influence of the other challenge areas, cognitive and behavioural challenges did not fully mediate the relationship between COVID-19 distress and expected GPA. However, metacognitive, motivational, and social and emotional challenges fully mediated the relationship between COVID-19 distress and expected GPA (indirect effects for metacognitive estimate: $-.002, p=0.4$; social and emotional estimate: $.003, \mathrm{p}=.02$; motivational: $-.003, \mathrm{p}=.002)$. Specifically, greater COVID-19 distress predicted higher levels of metacognitive challenges $\left(b_{3}=.23^{* *}, p<.001\right)$, which in turn predicted lower GPA $\left(c_{3}=-.14^{*}, p<.05\right)$. Similarly, greater COVID-19 distress predicted more motivational challenges $\left(b_{5}=.27^{* *}, p<.001\right)$, which in turn was related to lower expected GPA $\left(c_{5}=-.23^{*}, p<.05\right)$. However, while greater COVID19 distress predicted more social and emotional challenges $\left(b_{6}=.42^{* *}, p<.001\right)$, this increase in turn was related to higher expected GPA $\left(c_{6}=.14^{*}, p<.05\right)$.

\section{Figure 3}

Mediating Effect of Academic Challenges Subtypes on the Relationship Between COVID-19 Distress and Self-Reported GPA

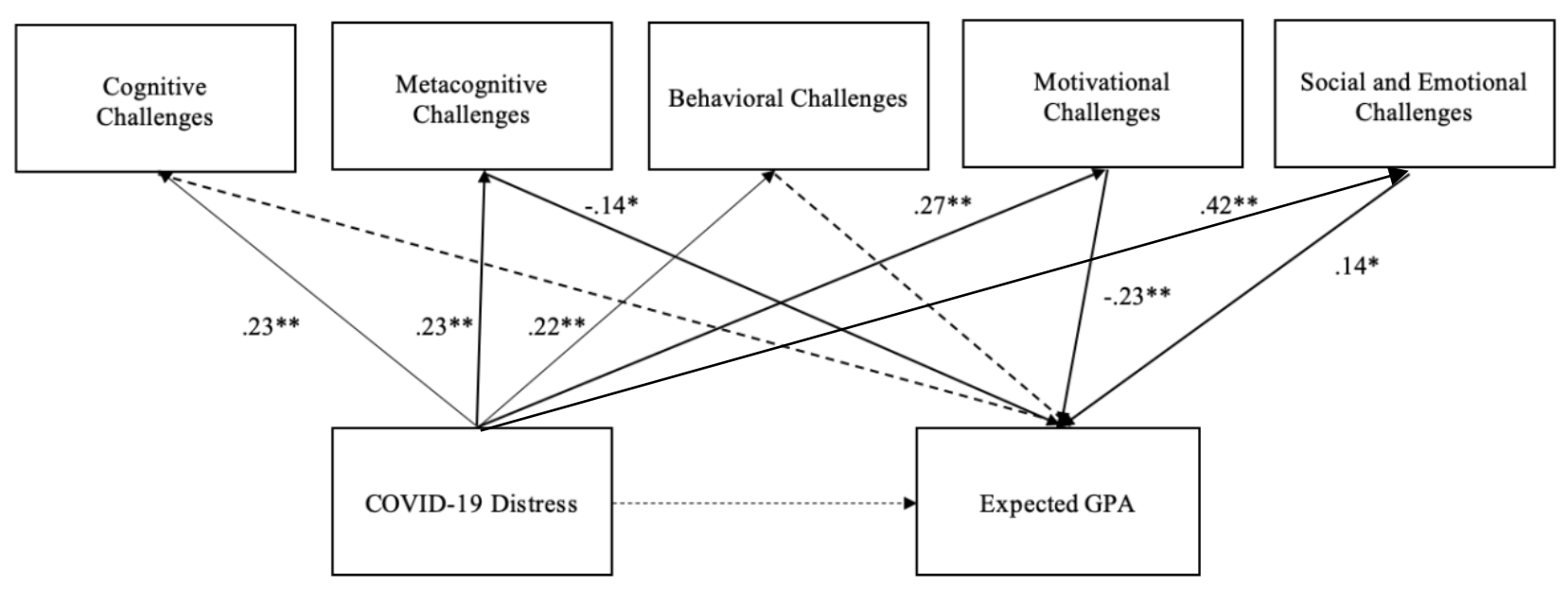

Note. Only estimates for significant pathways are presented. All correlations between academic challenges were estimated and significant but are not presented. Dashed lines represent nonsignificant pathways. ${ }^{*} p<.05 ; * * p<.001$

\section{Discussion}

Consistent with previous COVID-19 research, students are being impacted negatively by COVID-19 distress (Cao. et al., 2020; Li et al., 2020; Meo et al., 2020), which in turn is influencing their academic performance (Brackney \& Karabenick, 1995; Lloyd et al., 1980; Meo et al., 2021). Our findings also show that three specific academic challenges may be more related to COVID19 stressors than others. In particular, motivational, meta-cognitive, and social and emotional challenges emerged as the most salient mediators between COVID-19 and GPA. It is essential to 
recognize that academic challenges are a common occurrence for all students; those who persist and engage in strategies to help reduce challenges see a higher academic performance.

Motivation includes will, desire, and confidence to exert effort while studying. Our findings show that as COVID-19 distress increased, so did motivational challenges. The pandemic disrupting regular routines likely influenced students' motivation. As mentioned, students have reported having negative perceptions of the RCL shift (Blizak et al., 2020); further, they believe that they are getting a lower quality of learning, consequently putting a lower value on their schoolwork (Langegård et al., 2021). Negative emotions, like anxiety, may impact academic achievement by reducing intrinsic motivation and producing task-irrelevant thinking (Pekrun et al., 2002). Students who place a higher value on their academic tasks have greater self-regulated motivation (Paulino et al., 2017). Thus, students in the RCL era who face new tasks and learning structures expect their motivation to decrease. As students are facing problems in motivational challenges, they may see a drop in their expected GPA. In online settings, students with higher motivation have higher academic success and satisfaction (Cho \& Heron, 2015).

Meta-cognitive challenges were also a significant mediator between COVID-19 distress and expected GPA. Metacognitive factors include (1) planning by developing strong task understanding, (2) self-monitoring and self-awareness about what is working, and (3) strategy knowledge and choice. Students who use metacognitive strategies during RCL have higher intrinsic motivation and manage their time and tasks (Pelikan et al., 2021). Students in the remote COVID-19 learning era are experiencing a new and unique learning experience. Additionally, students must maintain their GPA and complete academic responsibilities. However, students have frequently reported procrastination and trouble focusing (Lie et al., 2021). RCL has increased psychological distress, which impedes students' ability to plan and monitor their online courses effectively. Studies have shown that students who are more skilled in balancing their schedules show higher academic achievement than students who are less skilled (Santhanam et al., 2008). In the context of RCL, students who received training in time management skills and organizing tasks felt better prepared to tackle academic tasks (Tobar et al., 2021).

Contrary to our prediction, while more significant COVID-19 distress predicted more social and emotional challenges, these challenges were associated with higher GPA. It may be that students prioritize academics at the expense of their mental health and relationships. Since students are adjusting to a new learning environment (Blizak et al., 2020) and attempting to keep their GPA high (Cao et al., 2020), they may be studying longer hours. Sadly, students may face burnout during their semesters. Burnout is prolonged exposure to chronic emotional and interpersonal stressors in the working environment (Zis et al., 2020). Research regarding COVID-19 and burnout in students found that burnout, cynicism towards academia, and emotional exhaustion increased during COVID-19. Consequently, mental health levels may deteriorate (Zis et al., 2020). Universities must offer mental health tips and services to provide more accessible and accommodating resources during this time.

Behaviour and cognitive challenges were not significant mediators over and above metacognitive, motivational, and social and emotional challenges. It may be that COVID-19 learning and distress have not drastically changed students' learning behaviours. As many students may be concerned about COVID-19, some studies have found that the casual nature of RCL leads to lower amounts of stress (Son et al., 2020). Even though classes are offered online, ultimately, course material and content are relatively similar to face-to-face classes; the significant difference is the layout of assignments and tests. During RCL learning, open-book assignments and tests are more common; thus, students are not required to prep for exams as diligently and thoroughly as they are 
for in-person tests because they can look-up their answers, rather than relying on their knowledge. Further, students may be cheating during their graded work (Gonzalez et al., 2020). Motivational, metacognitive, and social and emotional challenges may be more prominent than behavioural and cognitive challenges in adjusting to the RCL shift. Behavioural and cognitive strategies are commonly taught across academic careers; thus, students are comfortable managing these challenges.

Although the study examined COVID-19 psychological distress, there may also be variables that confound this construct, such as pandemic fatigue. Pandemic fatigue is exhaustion due to the COVID-19 pandemic, which is overwhelming because of disruptions in routines, social isolation, and unpredictability of what is ahead (Australian Psychological Survey, 2020). Pandemic fatigue is related to tiredness, physical exhaustion, headaches, body pains, or decreased motivation (Labrague \& Ballad, 2021).

This study highlights the need to develop resources to help students manage and cope with their academic challenges. Students who are enrolled in intervention programs that teach and develop strong learning habits and strategies report greater knowledge of self-regulated learning (SRL) strategies, greater use of said strategies, and more time studying (González-Pienda et al., 2014). SRL is a dynamic and context-specific process as learners adjust to a new task and situation at hand (Winne \& Hadwin, 1998). Specifically, SRL is guided by metacognition, motivation, and strategic action, connected to regulating one's cognition, behaviour, and socio-emotional factors (Winne, 2018; Winne \& Hadwin, 1998; Zimmerman, 2008). Being self-regulated learners provides building blocks for students to plan, monitor, manage thinking, behaviour, and emotions as they engage in their learning, which will then inevitably reduce academic challenges (Hadwin \& Winne, 2012). Finally, it is essential for educators to understand the specific problems students face in their academic work before designing learning strategy intervention programs to support their academic challenges (Hadwin et al., 2019).

\section{Conclusion}

In conclusion, students learning and studying within the RCL era are facing heightened stress and psychological distress due to the COVID-19 outbreak (Meo et al., 2020), which has impacted their mental health (Hasan \& Bao, 2020; Meo et al., 2020) and academic performance (Hasan \& Bao, 2020). This study investigated how different academic challenges (cognitive, motivational, socio-emotional, metacognitive, and behavioural) mediate the relationship between COVID-19 psychological distress and academic performance.

Our results show that motivational, meta-cognitive, and social and emotional challenges emerged as the most salient mediators between COVID-19 and GPA. As motivational and metacognitive challenges increased, COVID-19 distress consequently increased. However, as COVID19 distress increased, social and emotional factors were associated with higher GPA. Students are facing more mental health struggles during the pandemic (Meo et al., 2020); however, we theorize that students are prioritizing their schoolwork over their mental health and well-being. Behavioural and cognitive challenges were not significant mediators. It may be that COVID-19 learning and distress has not drastically changed students learning behaviours.

This study highlights the importance of teaching SRL strategies to help students manage and cope with their academic challenges and allow students to engage and control their own learning process (Jansen et al., 2019). Students who have SRL training and understanding report higher declarative knowledge and more time studying (Gonzalez et al., 2020). At the time of 
writing, students may be doing a hybrid of online and in-person classes and have trouble adjusting back. Universities should provide resources to help students adjust and transition back into a traditional learning setting. 


\section{References}

Australian Psychological Society. (2020). Managing lockdown fatigue. Australian Psychological Society. https://www.psychology.org.au/getmedia/74e7a437-997c-4eea-a49c30726ce94cf0/20APS-IS-COVID-19-Public-Lockdown-fatigue.pdf

Blizak, D., Blizak, S., Bouchenak, O., \& Yahiaoui, K. (2020). Students' perceptions regarding the abrupt transition to online learning during the COVID-19 pandemic: Case of faculty of chemistry and hydrocarbons at the university of Boumerdes-Algeria. Journal of Chemical Education, 97(9), 2466-2471. https://doi.org/10.1021/acs.jchemed.0c00668

Brackney, B. E., \& Karabenick, S. A. (1995). Psychopathology and academic performance: The role of motivation and learning strategies. Journal of Counseling Psychology, 42(4), 456465. https://doi.org/10.1037/0022-0167.42.4.456

Briggs, A. R. J., Clark, J., \& Hall, I. (2012). Building bridges: Understanding student transition to university. Quality in Higher Education, 18(1), 3-21. https://doi.org/10.1080/13538322.2011.614468

Cao, W., Fang, Z., Hou, G., Han, M., Xu, X., Dong, J., \& Zheng, J. (2020). The psychological impact of the COVID-19 epidemic on college students in China. Psychiatry Research, 287, 112934. https://doi.org/10.1016/j.psychres.2020.112934

Cho, M.-H., \& Shen, D. (2013). Self-regulation in online learning. Distance Education, 34(3), 290-301. https://doi.org/10.1080/01587919.2013.835770

Dodd, R. H., Dadaczynski, K., Okan, O., McCaffery, K. J., \& Pickles, K. (2021). Psychological wellbeing and academic experience of university students in Australia during COVID-19. International Journal of Environmental Research and Public Health, 18(3), 866. https://doi.org/10.3390/ijerph18030866

Dörrenbächer, L., \& Perels, F. (2016). Self-regulated learning profiles in college students: Their relationship to achievement, personality, and the effectiveness of an intervention to foster self-regulated learning. Learning and Individual Differences, 51, 229-241. https://doi.org/10.1016/j.lindif.2016.09.015

Gonzalez, T., de la Rubia, M., Hincz, K., Lopez, M. C., Subirats, L., Fort, S., \& Sacha, G. M. (2020). Influence of COVID-19 confinement in students' performance in higher education. https://doi.org/10.35542/osf.io/9zuac

González-Pienda, J. A., Fernández, E., Bernardo, A., Núñez, J. C., \& Rosário, P. (2014). Assessment of a self-regulated learning intervention. The Spanish Journal of Psychology, 17. https://doi.org/10.1017/sjp.2014.12 
Hadwin, A. F., Davis, S. K., Bakhtiar, A., \& Winne, P. H. (2019). Academic challenges as opportunities to learn to self-regulate learning. In H. Askell-Williams \& J. Orrell (Eds.), Problem solving for teaching and learning, (pp. 34-47). https://doi.org/10.4324/9780429400902-4

Hadwin, A. F., Winne, P. H., Stockley, D. B., Nesbit, J. C., \& Woszczyna, C. (2001). Context moderates students' self-reports about how they study. Journal of Educational Psychology, 93(3), 477-487. https://doi.org/10.1037/0022-0663.93.3.477

Hasan, N., \& Bao, Y. (2020). Impact of “e-Learning crack-up” perception on psychological distress among college students during COVID-19 pandemic: A mediating role of "fear of academic year loss." Children and Youth Services Review, 118, 105355. https://doi.org/10.1016/j.childyouth.2020.105355

Jansen, R. S., van Leeuwen, A., Janssen, J., Jak, S., \& Kester, L. (2019). Self-regulated learning partially mediates the effect of self-regulated learning interventions on achievement in higher education: A meta-analysis. Educational Research Review, 28, 100292. https://doi.org/10.1016/j.edurev.2019.100292

Kim, H. H., \& Jung, J. H. (2020). Social isolation and psychological distress during the COVID19 pandemic: A cross-national analysis. The Gerontologist, 61(1), 103-113. https://doi.org/10.1093/geront/gnaa168

Labrague, L. J., \& Ballad, C. A. (2021). Lockdown fatigue among college students during the COVID-19 pandemic: Predictive role of personal resilience, coping behaviors, and health. Perspectives in Psychiatric Care, 1-8. https://doi.org/10.1111/ppc.12765

Langegård, U., Kiani, K., Nielsen, S. J., \& Svensson, P.-A. (2021). Nursing students’ experiences of a pedagogical transition from campus learning to distance learning using digital tools. BMC Nursing, 20(1). https://doi.org/10.1186/s12912-021-00542-1

Li, H., Hafeez, H., \& Zaheer, M. A. (2021). COVID-19 and pretentious psychological wellbeing of students: A threat to educational sustainability. Frontiers in Psychology, 11. https://doi.org/10.3389/fpsyg.2020.628003

Lloyd, C., Alexander, A. A., Rice, D. G., \& Greenfield, N. S. (1980). Life events as predictors of academic performance. Journal of Human Stress, 6(3), 15-25. https://doi.org/10.1080/0097840x.1980.9936094

Meo, S. A., Abukhalaf, D. A., Alomar, A. A., Sattar, K., \& Klonoff, D. C. (2020). COVID-19 pandemic: Impact of quarantine on medical students' mental wellbeing and learning behaviors. Pakistan Journal of Medical Sciences, 36(COVID19-S4). https://doi.org/10.12669/pjms.36.covid19-s4.2809 
Paulino, P., Sá, I., \& Lopes da Silva, A. (2017). Students' motivation to learn in middle school a self-regulated learning approach. Electronic Journal of Research in Education Psychology, 14(39). https://doi.org/10.25115/ejrep.39.15169

Pekrun, R., Goetz, T., Titz, W., \& Perry, R. P. (2002). Academic emotions in students' selfregulated learning and achievement: A program of qualitative and quantitative research. Emotions in Education, 91-106. https://doi.org/10.4324/9781410608628-4

Pelikan, E. R., Lüftenegger, M., Holzer, J., Korlat, S., Spiel, C., \& Schober, B. (2021). Learning during COVID-19: The role of self-regulated learning, motivation, and procrastination for perceived competence. Zeitschrift Für Erziehungswissenschaft, 24(2), 393-418. https://doi.org/10.1007/s11618-021-01002-X

Qiu, J., Shen, B., Zhao, M., Wang, Z., Xie, B., \& Xu, Y. (2020). A nationwide survey of psychological distress among Chinese people in the COVID-19 epidemic: Implications and policy recommendations. General Psychiatry, 33(2). https://doi.org/10.1136/gpsych-2020100213

Santhanam, R., Sasidharan, S., \& Webster, J. (2008). Using self-regulatory learning to enhance e-learning-based information technology training. Information Systems Research, 19(1), 26-47. https://doi.org/10.1287/isre.1070.0141

Schraml, K., Perski, A., Grossi, G., \& Makower, I. (2012). Chronic stress and its consequences on subsequent academic achievement among adolescents. Journal of Educational and Developmental Psychology, 2(1). https://doi.org/10.5539/jedp.v2n1p69

Son, C., Hegde, S., Smith, A., Wang, X., \& Sasangohar, F. (2020). Effects of COVID-19 on college students' mental health in the United States: Interview survey study. Journal of Medical Internet Research, 22(9). https://doi.org/10.2196/21279

Tobar, C., Garcés, M. S., Crespo-Andrade, M. C., \& Sisa, I. (2021). The impact of strengthening study habits for medical students during COVID-19 academic transition: A mixed-methods study. Medical Science Educator, 31(3), 1083-1090. https://doi.org/10.1007/s40670-021$\underline{01277-\mathrm{Z}}$

Weinstein, C. E., Acee, T. W., Jung, J., \& Dearman, J. K. (2011). Strategic and self-regulated learning for the 21st century: The merging of skill, will and self-regulation. In Morrison, B. (Ed.), Independent language learning: Building on experience, seeking new perspectives, (pp. 41-54). Hong Kong Scholarship. https://doi.org/10.5790/hongkong/9789888083640.003.0004

Weinstein, C. E., Husman, J., \& Dierking, D. R. (2000). Self-regulation interventions with a focus on learning strategies. In Boekaerts, M., Pintrick, P.R. \& M. Zeidner (Eds.), Handbook of self-regulation (pp. 727-747). Academic Press. https://doi.org/10.1016/b978$\underline{012109890-2 / 50051-2}$ 
Winne, P. H. (2018). Cognition and metacognition within self-regulated learning. In Alexander, P. A., Schunk, D. H., \& J. A. Greene (Eds.), Handbook of self-regulation of learning and performance (2nd ed., pp. 36-48). Routledge. https://doi.org/10.4324/9781315697048-3

Winne, P. H., \& Hadwin, A. F. (1998). Studying as self-regulated learning. In Hacker, D. J., Dunlosky, J., \& A. C. Graesser (Eds.), Metacognition in educational theory and practice, (1st ed., pp. 291-318). Routledge. https://doi.org/10.4324/9781410602350-19

Winne, P. H., \& Hadwin, A. F. (2008). The weave of motivation and self-regulated learning. In D. H. Schunk \& B. J. Zimmerman (Eds.), Motivation and self-regulated learning: Theory, research, and applications (pp. 297-314). Lawrence Erlbaum Associates Publishers.

Zimmerman, B. J. (2008). Investigating self-regulation and motivation: Historical background, methodological developments, and future prospects. American Educational Research Journal, 45(1), 166-183. https://doi.org/10.3102/0002831207312909

Zis, P., Artemiadis, A., Bargiotas, P., Nteveros, A., \& Hadjigeorgiou, G. M. (2020). Medical studies during the COVID-19 pandemic: The impact of digital learning on burnout and mental health. https://doi.org/10.21203/rs.3.rs-63097/v1 